Doi: 10.5212/PublicatioCi.Soc.v.21i1.0008

\title{
FLUXOS IDENTITÁRIOS A PARTIR DO REFERENCIAL LINGUÍSTICO E INTERFACES CULTURAIS: UM ESTUDO SOBRE TRANSFORMAÇÕES E DESLOCAMENTOS CULTURAIS ENTRE DESCENDENTES DE ALEMÃES EM JOINVILLE-SC
}

\section{IDENTITY FLOWS FROM REFERENCE LANGUAGE AND CULTURAL INTERFACE: A STUDY ON CHANGES AND CULTURAL SHIFTS AMONG GERMAN DESCENDANTS IN JOINVILLE-SC}

\author{
Jailson Estevão dos Santos ${ }^{1}$ \\ Taiza Mara Rauen Moraes $^{2}$
}

\begin{abstract}
RESUMO
No presente artigo, os focos de análise são referenciais linguísticos associados a fluxos identitários que motivaram transformações, deslocamentos e criação de mitos entre descendentes de alemães em Joinville-SC. O período investigado é o do "Estado Novo", atrelado à campanha de nacionalização do governo Getúlio Vargas. Momento de transformações políticas e sociais que culmina na proibição do uso da língua alemã no Brasil, amplamente falada em Joinville/SC, repercutindo em mudanças identitárias pelo sufocamento linguístico e cultural.
\end{abstract}

Palavras-chave: Identidade. Cultura. Referencial linguístico.

\begin{abstract}
This article focuses on the linguistic reference flows associated with identity that motivated transformations, displacements and the creation of myths among descendants of Germans in Joinville-SC. The period investigated is that of the "Estado Novo" (New State) linked to the nationalization campaign of the Getúlio Vargas government. The "Estado Novo" was a moment of political and social changes that culminated with the prohibition of the use of German language in Brazil, widely spoken in Joinville/SC. This prohibition affected identity changes caused by the process of linguistic and cultural oppression.
\end{abstract}

Keywords: Identity. Culture. Linguistic reference.

\footnotetext{
${ }^{1}$ Teólogo e professor (Português e literaturas vernáculas), especialista em educação. Mestrando em Patrimônio Cultural e Sociedade: UNIVILLE - Universidade da região de Joinville. Email: jeste@ig.com.br

${ }^{2}$ Professora titular do curso de Letras e do Mestrado - UNIVILLE - Universidade de Região de Joinville, com mestrado e doutourado em Teoria da Literatura pela Universidade Federal de Santa Catarina. Coordena o Comitê Proler Joinville e o Programa Institucional de Incentivo a Leitura da Univille. Desenvolve projetos de pesquisas na área de Letras e Cultura, com ênfase em Leitura em Meios Eletrônicos, Memória e Gênero. E-mail: taiza.mara@univille.br
} 


\section{Introdução}

O presente estudo é decorrente da análise do referencial linguístico de sete entrevistas efetuadas com descendentes de alemães que frequentam a Sociedade Cultural Alemã de Joinville - DKVJ (Deutscher Kulturverein Joinville), entidade fundada em 03 de outubro de 1999, que consiste em um espaço de portas abertas com atividades que visam à preservação de memórias da "cultura germânica".

A análise das representações linguísticas reflete as transformações e deslocamentos culturais e identitários entre descendentes que viveram sob a égide do período em que vigorou a Campanha de Nacionalização do governo Vargas e suas consequências mais imediatas.

Por referencial linguístico entende-se, aqui, não o sistema linguístico em si, com as suas características opositivas, "sincrônicas e diacrônicas", como entende Saussure (1975, p. 96-124), mas a língua enquanto patrimônio cultural como instrumento, tanto de comunicação como de identificação de um povo e também de mitos; um elemento de preservação da história e de apropriação de narrativas em diversidade de significações. Conforme Hobsbawn (1984, p. 15), "[...] muitas instituições políticas, movimentos ideológicos e grupos - inclusive o nacionalismo sem antecessores tornaram necessária a invenção de uma continuidade histórica". Daí a ideia de patrimônio como herança de um passado glorioso.

As entrevistas permitem abrir espaços de reflexão sobre o estudo da língua como fenômeno cultural e condutor de valores. Destacam-se aspectos híbridos formados por "cruzamentos intensos e instabilidade cultural", como entendeu Canclini (2008, p. 326). O estudo e análise aqui apresentados visam, portanto, à compreensão de fenômenos sociais associados à obrigatoriedade de se falar o português como uma segunda língua. Os descendentes de alemães que viveram nesse período experimentaram mais de perto as consequências que se seguiram até o período pós-guerra. Alguns eram crianças na época, mas outros, já adolescentes, lembram-se de fatos que hoje se vinculam às suas memórias, os quais interferem nas reivindicações por eles compreendidas, como de necessidade ou de preservação de valores culturais associados à germanidade.
A motivação de investigações, envolvendo a área cultural pelo viés da linguística, explica-se pela minha condição de migrante nordestino, há 30 anos em vivências de transformações e deslocamentos identitários entre o Nordeste e o Sul do Brasil. Constatei, nessa convivência, memórias sobre a "cultura alemã" recuperadas com maior e menor intensidade em relação aos períodos históricos e, em especial, ao período do governo do presidente Getúlio Vargas, de 1930 a 1945.

O uso da Língua Alemã é um elo entre a comunicação dos entrevistados, pois três deles falam e escrevem na língua dos ancestrais. Esses dados subsidiam a compreensão da língua como fator de hegemonia ideológica que resultam em identidades culturais.

\section{Fluxos identitários entre descendentes de alemães em Joinville}

A atividade imigratória se destaca pelo seu caráter intenso na história de Joinville-SC. Tem início no final do século XIX com a colonização envolvendo estrangeiros europeus, continua no século XX, especialmente durante as duas guerras mundiais, e se repercute até à contemporaneidade com as relações interétnicas consequentes das diversas imigrações, bem como da atividade migratória em torno do trabalho e da indústria. A cidade vive uma diversidade cultural, um processo histórico que se dá na interação de fluxos identitários que envolvem questões ligadas à memória e à identidade cultural. $\mathrm{O}$ que se depreende, de modo geral, é que os entrevistados, em questões de "identidade cultural", falam do que filtraram da memória coletiva.

Resgatar os fluxos identitários e construir uma historiografia local tem sido o objetivo de algumas atividades realizadas por associações e entidades que buscam disseminar a "cultura alemã" em Joinville.

Em relação à memória e identidade, deve-se levar em consideração que, do ponto de vista do tempo presente, Joinville convive com uma mescla cultural devido às levas de migrantes, especialmente nas últimas quatro décadas, que criaram uma nova configuração identitária, sobretudo de aspecto cultural híbrido.

Prevalecem marcas do período histórico da Era Vargas no Brasil, em que se obrigou, por força de lei, 
uma interação cultural. Esse quadro veio a favorecer situações que ajudaram a forjar e suscitar mitos identitários por conta de algumas pressões como: obrigatoriedade do monolinguismo; proibição de se falar o alemão em contexto público, e até privado, como revela Clock (2009) no documentário "Sem Palavras", mostrando que até dentro de seus aposentos os alemães e seus descendentes sofreram perseguição para deixar de falar sua língua materna ${ }^{3}$; impedimento de participar dos eventos públicos como um brasileiro comum, sem os vestígios da cultura alemã. Trinks (2012) recorda que seu "pai chegou a ser preso", e Reis e Hardt (2012) constatam que os espaços e interlocutores da língua alemã diminuíram, ou seja, o mito de um modus vivendi é recuperado por essas memórias. Verifica-se, portanto, em todas essas circunstâncias, a existência da memória enquanto mito. Cada descendente de alemão se apropriou do seu discurso. Cada um elaborou o seu próprio sujeito, mas todos laboraram no campo da diferenciação. Tinham à sua frente um novo horizonte, mas, no passado, um referencial a que tentaram se apegar para traduzir suas memórias e modus vivendi. Tudo isso se assentou no campo da metalinguagem e hoje não passa de metamemória. "A metamemória, que é, por um lado, a representação que cada indivíduo faz de sua própria memória, o conhecimento que tem dela, e, de outro, o que diz dela [...]" (CANDAU, 2011, p. 23).

Nesse sentido, os sujeitos lembram o peso cultural de padrões educacionais. Bruhns (2012) afirma: "a gente adquire hábitos na infância e disciplina [...] Sou muito observadora e mantenho postura firme"; Trinks (2012) relembra que palavras em alemão foram descaracterizadas linguisticamente; Hardt (2012) suscita a prática dos casamentos que "deviam ser com cônjuges da mesma raça", recuperando o arianismo ${ }^{4}$; já Roskamp (2012), ao responder sobre os motivos que favoreceram a assimilação da língua portuguesa entre os imigrantes alemães e descentes, avalia que, em um primeiro momento, o processo foi decorrente de uma imposição política, embora posteriormente essa assimilação tenha ocorrido mais

\footnotetext{
3 Sem palavras - Documentário sob a direção de Kátia Clock pela Contraponto Produtora com apoio da Secretaria de Turismo, Esporte e Cultura de Santa Catarina em comemoração aos 180 anos de imigração alemã.

4 Arianismo: Termo que, do ponto de vista das teorias modernas das raças, refere-se ao povo alemão sem qualquer mistura étnica. Parte do pressuposto sobre a descendência dos Povos Árias, orientais e, portanto, sem qualquer ascendência judaica.
}

naturalmente: "acredito que os imigrantes e seus primeiros descendentes ficaram mais humildes e mais temerosos em se expressar no idioma de sua nova pátria. Depois, é claro, os brasileiros, filhos de imigrantes, adquiriram o ímpeto realizador".

É preciso fazer também um recorte na história, especialmente no que tange às pressões políticas do governo Getúlio Vargas. Nesse, em particular, há algumas considerações que podemos destacar com base na afirmação de Spinassé (2008, p. 127), quando registra que:

Os alemães emigraram para o Brasil por vários motivos, mas com um único objetivo: o de iniciar aqui uma vida nova e melhor. A pobreza predominava na Alemanha e os governos não davam conta de auxiliar e amparar a população. Essa situação emergencial era grave [...]. Por sua vez o Brasil, como um país jovem e de independência recém-declarada, necessitava de mais habitantes e de mais mão-de-obra para o imenso território. [...] $\mathrm{O}$ governo brasileiro enviou, então, agentes de imigração para a Europa para fazerem propaganda sobre o Brasil [...].

O mundo da década de 1940 e 1950 vivia a ebulição e expectativas políticas e ideológicas do Nazismo e do Fascismo que varriam a Europa. A linguagem foi um dos canais pelos quais os questionamentos suscitaram o autoritarismo. Os imigrantes alemães em Joinville, tanto no contexto da primeira quanto da segunda guerra mundiais, ao procederem a um deslocamento geográfico, o fizeram, entre outros motivos, fugindo, também, do jogo linguístico de poder. Os descendentes de alemães, naturalmente, receberam as informações desse processo pelo discurso doméstico. Portanto, sua convivência cultural não foi marcada pela neutralidade. Eles ocupam um lugar e tem uma ideologia formada.

Gallo (2011, p. 12) afirma: "Acredito que o modo como as coisas são faladas e silenciadas depende da posição que se ocupa ao falar ou calar. Não há dizer neutro, sem vínculo com a história". A língua era o recurso cultural real que os imigrantes tinham em termos efetivos de cultura a que eles poderiam se apegar para conviver e partilhar uma identidade cultural. Posteriormente, os descendentes ajudam a promover, em maior escala, o fluxo cultural de cunho material e imaterial, em suas diversas realizações. Segundo Coelho (1993, p. 62), 
Em Joinville, o "idioma alemão" foi predominante até o final da década de 30 , tanto na zona rural como na urbana, sendo utilizado no ensino (tanto nas escolas públicas como nas particulares), no comércio, nas repartições públicas e, obviamente no ambiente familiar. ${ }^{5}$

Apesar das diferenças dialetais, garantiu-se a sobrevivência na fase inicial da colonização, conforme Spinassé (2008). Naquele momento, a "linguagem", que deveria ser usada para a comunicação entre os seres humanos, tornou-se explicitamente um meio de dominação, de expressão de poder. As divergências, os consensos e as ideias transformaram-se em instrumentos de escravização, de hegemonia. Roskamp (2012) afirma que as mudanças iniciaram com a proibição do uso da língua em lugares públicos e em atividades teatrais"; Voigt (2012) acrescenta dois fatores para que o uso da língua alemã fosse superada pelo uso da língua portuguesa: "respeito aos brasileiros e o convívio com pessoas que não falam alemão. Evitar discriminação e constrangimento".

Nesse sentido, a língua tem sido motivo de estudos de alguns teóricos que revelam a ambivalência de aspectos hegemônicos nos interesses de cada grupo falante. "A palavra é o fenômeno ideológico por excelência", assim afirma Bakhtin (1988, p. 36). Ainda é pela utilização da língua que os descendentes de alemães tentam manter acesas suas memórias culturais, razão pela qual a Sociedade Cultural Alemã de Joinville (DKVJ) mantém um encontro semanal para conversação em língua alemã. $\mathrm{O}$ espaço é aberto a quem se interessa pela cultura alemã e tem algum domínio da língua.

De modo geral, não é muito diferente para outros povos. Parece haver sempre um conflito entre a "memória oficial" e a "coletiva", criando, assim, as "memórias subterrâneas", (POLLAK, 1989, p. 4). Conceitos relativos, pois, dependem da posição e leitura dos sujeitos ativos e passivos da história. $\mathrm{O}$ que foi excludente para uma coletividade é visto em caráter de "justiça" pela cultura dominante e, por outro lado, as razões das culturas minoritárias e tentativas de invenções identitárias são evocadas como elementos de justiça, se dominantes, e de injustiça, se dominadas. Há, contudo, algum silêncio que per-

\footnotetext{
${ }^{5}$ Citado também em: COELHO, Ilanil. É proibido ser alemão: é tempo de abrasileirar-se. In: GUEDES, Sandra P. L. de Camargo. (Og). História de (I) migrantes, o cotidiano de uma cidade. Joinville: Univille. 2005.
}

manece no ar, fenômeno explicável face às opressões que os imigrantes sofreram. Isso revela que há uma tentativa de fazer valer a existência de uma "memória subterrânea". Esse silêncio é lembrado por Pollak $(1989$, p. 5) como portador de lembranças que, mais cedo ou mais tarde, afloram na comunicação social.

O longo silêncio sobre o passado, longe de conduzir ao esquecimento, é a resistência que uma sociedade civil impotente expõe ao excesso de discursos oficiais. Ao mesmo tempo, ela transmite cuidadosamente as lembranças dissidentes nas redes familiares e de amizades, esperando a hora da verdade e da redistribuição das cartas políticas e ideológicas.

Se, por um lado, todo o esforço de manutenção e preservação da cultura alemã precisa ser reconhecido como efetivo em todos os acontecimentos e eventos com essa finalidade, por outro, é necessário compreender, no que diz respeito à memória e identidade, que o discurso está inserido no contexto que Candau (2011, p. 21) chama de "retóricas holistas" e, portanto, esses discursos são colocados por ele como representações.

A memória pode ser mais ou menos convergente entre os indivíduos de um grupo e, por isso, diferenciada em forte e fraca ou, ainda, como "metamemória", esta última para se referir à representação da memória de "alto nível". Nesse sentido, o que se pode depreender é que a metamemória prevalece nos discursos das entrevistas analisadas. Afirmações como: "Os descendentes de alemães são perseverantes" (BRUHNS, 2012); "A preservação da memória cultural das origens" (VOIGT, 2012); "Preservar a cultura e exercitar o que aprendeu-se" (BUTZKE, 2012); "O alemão era a língua mais usada. E seriedade, a modéstia e a determinação nos cativavam. [...] Depois, é claro, os brasileiros filhos de imigrantes, adquiriram o ímpeto realizador" (ROSSKAMP, 2012); denotam falas demarcadas por um conceito ideológico, por uma representação linguística de interesses hegemônicos.

\section{Intercâmbio linguístico e cultural entre descendentes de alemães}

O referencial linguístico é tomado aqui para lembrar que foi um dos fatores mais problemáticos no início da colonização joinvilense no séc. XIX. As 
relações da língua alemã frente à língua portuguesa, ambas vistas como fundamentos identitários, foram motivos de discussões no campo da cultura, questões que permanecem até os dias atuais. "O componente étnico de maior peso para identificar a volksgemeinschaft $t^{6}$ é a língua alemã, nesse sentido ela supera a questão racial" (SEYFERTH, 1981, p. 215).

Os imigrantes viveram, por certo tempo, um tanto isolados em suas comunidades e em áreas florestais (SEYFERTH, 1981). Isso dificultou o intercambio linguístico com a Língua Portuguesa. Foi por meio do programa de nacionalização, outorgado com o Estado Novo, que o aprendizado começou a surgir. Conforme afirma Rost (2008 p. 215),

Somente a partir do século XX surgiu o interesse do governo brasileiro e das comunidades formadas por imigrantes europeus pela aprendizagem do português. No governo Vargas, todavia, o português foi imposto como a língua da educação e dos contextos formais nas comunidades de imigração.

A interação com os falantes nativos passou a constituir uma carência no momento histórico em que o estado brasileiro impôs aos imigrantes a Língua Portuguesa como oficial. A partir de então, a língua passa a exercer um papel ainda mais preponderante na relação entre a comunidade alemã e brasileira. Por questão de sobrevivência, todos tiveram que aceitar a realidade de aprender a nova língua. Porém, como já foi dito, esse processo deu-se em meio a tensões sociais e políticas. Historicamente, pode-se dizer que "a política linguística para essas populações de imigrantes alternou entre momentos de indiferença e de imposição severa de medidas prescritivas e proscritivas." (ALTENHOFEN, 2004, p.83). Com a obrigatoriedade do ensino da língua portuguesa para os imigrantes, as alterações na área linguística começam, nitidamente, a acontecer. Isso é confirmado por Butzke (2012), ao citar que foi "no início das aulas" que ocorreu a "mudança" de percepção de valores identitários.

A língua e sua expressão têm sido, até o presente, uns dos mais importantes meios pelos quais o processo identitário se estabelece, ainda que no convívio de variações ou de expressões de força. No dizer de Bakhtin (1988, p.14), “A fala é o motor das transformações linguísticas, [...] inseparável de ou-

\footnotetext{
${ }^{6}$ Termo que significa comunidade. (SEYFERTH, 1981 p. 125).
}

tras formas de comunicação, implica conflitos, relações de dominação [...]”.

A língua como meio comunicativo não necessita de mudanças, estas ocorrem por conta da dinâmica humana. Ela é um elemento histórico e cultural que pode provocar transformações e deslocamentos na identidade cultural. Porém, como afirma Saussure (1975, p. 88), “de todas as instituições sociais é a que oferece menos oportunidade às iniciativas. [...] forma um todo com a vida da massa social, e esta, sendo naturalmente inerte, aparece antes de tudo como um fator de conservação".

As mudanças que ocorreram com o passar dos anos nos usos e costumes, ou mesmo na linguagem, como fatores de identidade entre descendentes de alemães em Joinville-SC, foram provenientes das diferenças e das pressões culturais. Quando a língua alemã foi proibida, fruto da instituição do regime do Estado Novo e do consequente programa de nacionalização, as mudanças com relação à comunicação aconteceram, porém, como um projeto de Estado e concepções em disputa pela hegemonia. Essa proibição reverteu-se fortemente, agindo como um golpe no sistema cultural. Para os imigrantes e seus descendentes, a língua era o mais importante patrimônio cultural que os unia. Conforme Seyferth (1981, p. 101), a partir de 1930 a língua assume um lugar preponderante "nas discussões sobre o deutschtum", quando se constata a "ameaça" iminente da "nacionalização do ensino" com discursos que visavam a "uma comunidade nacional com base numa língua comum e numa cultura comum". A autora destaca um texto publicado em importantes jornais da época, intitulado "Os dez mandamentos do teuto-brasileiro", o qual nominava, em quatro itens, questões ligadas à afirmação da preservação da língua alemã a qualquer custo. Esses itens rezam sobre a fala, a escrita, a promoção e o esforço para manter o nome próprio linguisticamente caracterizado pelos originais da língua alemã.

Porém, analisando pela ótica da história, o governo brasileiro não teve muitas opções com respeito ao considerado "perigo alemão". Conforme análise feita por De Luca (2011, p. 282), havia uma tentativa de criação de uma província alemã no Brasil.

\footnotetext{
Termo que significa "princípio de germanidade" conforme explicado por Coelho (2008) em entrevista concedida In: Raquel S. Santiago. Tempos de Joinville. Joinville: Univille, 2008, p. 32). (SEYFERTH 1981, p. 3).
} 
A autora, alerta sobre o avanço da Alemanha e cita uma fala num artigo da Revista do Brasil de 1940, objeto de sua pesquisa, cujos termos transcrevo.

Herman Rausching transmitiu a todos os povos americanos, no Hitler disse-me, oportunas advertências sobre os planos do Führer na América, concebidos em 1933, logo no início de seu governo. Naturalmente o Brasil vinha em primeiro lugar. Hitler pensava em edificar uma nova Alemanha em nosso país. "Ai encontraremos tudo de que tivermos necessidade". Para o Führer existem aqui todas as condições de uma revolução que lhe permitiria, em alguns anos "transformar o Estado governado por mestiços corruptos em um domínio germânico".

Algumas atividades e literaturas desta época deixam claro que havia "uma tentativa de criação de uma província de ideologia nazista, um esquema de nação", influência de veiculações literárias identificadas com fanatismo pró Alemanha e os ideais da Liga Pangermânica, conforme afirma Seyferth (1981).

É sensível o questionamento presente nas entrevistas analisadas em que os sujeitos apontam o cancelamento de eventos culturais, especialmente as festas realizadas no âmbito da família, como um dos fatos que mais marcaram, com revolta, suas memórias sobre o período da proibição da língua. Butzke (2012) coloca a "visitação aos amigos e conhecidos" como prática que hoje já não realiza mais; e Voigt (2012) relembra as festas e bailes em Clubes de Caça e Tiro 'schützenverein' e 'schützenfest'. 'Torneios, festas e bailes de Rei de Tiro ao alvo".

Embora isso tenha acontecido como uma intervenção dos imigrantes para amenizar o conflito, o processo não foi tão simples. O quadro foi assemelhado a um trem, cuja entrada na estação final era extremamente duvidosa. Exemplo introduzido pela cinematografia no filme de Mihaileanu (1998), no qual um personagem interpretando um rabi, é interceptado, em meio a uma reunião, por uma mãe que pede silêncio para não acordar as crianças. Diz ele: "Como poderemos pensar sem falar?". O discurso pedia licença num contexto proibitivo. ${ }^{8}$

Hoje, sabe-se que muitas coisas deixaram de ser transmitidas em discursos ou práticas culturais

\footnotetext{
8. O trem da vida. Filme de Radu Mihaileanu, - Belgica, França e Holanda, 1998; trata da questão da cultura e das imbricações linguísticas no jogo de poder.
}

comuns, devido às dificuldades de aceitar a interação cultural. Uma visão mais abrangente do mundo, suas relações subjetivas e objetivas, é observada entre os sujeitos entrevistados, especialmente quando lamentam a proibição da língua com consequências imediatas nas interrupções das atividades culturais desenvolvidas em língua alemã, as dificuldades do impedimento de comunicação com os falantes da língua materna e, ainda, as dificuldades pela necessidade de se falar o português, uma língua que não dominavam. Situações complexas presentes na relação entre o uso de uma língua materna e uma segunda língua, nesse caso, da língua alemã, e a interferência obrigatória da língua portuguesa, como no exemplo de Reis (2012), que lembra como "Frau Schroeder (mãe) passou a ser Dona Gertrudes e Seu Schroeder passou a ser Seu Conrado".

Naquele momento, o governo brasileiro se apropriava do poder para atingir os imigrantes no que tinham de mais especial para a transmissão cultural: a língua. Então, o poder dominante oprimiu linguística e culturalmente, confirmando que "a palavra revela-se no momento de sua expressão, como o produto da interação viva das forças sociais." (BAKHTIN, 1988, p. 66).

O tempo se encarregou de criar matizes e releituras. Os deslocamentos e transformações em meio aos fluxos identitários, movidos pela experiência linguística, instalaram e definiram novas significações e visões de mundo. A maioria delas, apropriadas da linguagem do mito.

O "sistema mítico" se difere do sistema linguístico, segundo Barthes(2001). Neste, o significante é de ordem "puramente psíquica", imotivado, e o significado é de ordem conceitual, ou seja, serve-se dos sentidos aplicados intencionalmente pelos indivíduos. Naquele, as relações associativas fazem surgir várias significações extraídas dos significados (determinados), e da criação "motivada" de outros significantes, uma cadeia de descobertas simultâneas.

A mensagem que subjaz os questionamentos presentes nas releituras das novas narrativas feitas com base na interação com o novo é reinventada à luz da história, da sociedade, das necessidades emergentes. Nesse sentido, o mito não é só uma linguagem; é, sobretudo, uma fala, para concordar com Barthes (2001 p. 132), “[...], pois é a história que transforma o real em discurso [...]. Longínqua ou não, a mitolo- 
gia só pode ter um fundamento histórico, visto que o mito é uma fala escolhida pela história [...]".

Dentro desse patamar, o câmbio linguístico foi gradativo. Aos poucos, os imigrantes e seus descendentes foram construindo novas narrativas e redirecionando o seu discurso. Tornou-se, então, perceptível o intercâmbio identitário, tendo como mola propulsora dessa transformação o referencial linguístico, embora o grupo identitário conserve-se diante dos efeitos sociais e econômicos, conforme proposição de Bourdieu (2002 p.125).

A revolução simbólica contra a dominação simbólica e os efeitos de intimidação que ela exerce tem em jogo não, como se diz, a conquista ou a reconquista de uma identidade, mas a reapropriação colectiva deste poder sobre os princípios de construção e de avaliação da sua própria identidade, de que o dominado abdica em proveito do dominante enquanto aceita ser negado ou negar-se (e negar os que, entre os seus, não querem ou não podem negar-se) para se fazer reconhecer.

A interferência mais imediata e acentuada que se nota, por meio do câmbio linguístico, acontece na identidade. Consequentemente, há novas identidades em ação, novos discursos, e uma nova interpretação dos fatos da época em estudo, pois os sujeitos, conscientes das mudanças que aconteceram e do modo como aconteceram, hoje aplicam outros olhares numa análise diacrônica.

Os descendentes de imigrantes alemães que viveram em Joinville nas décadas de 1940 e 1950 acompanharam de perto as influências pós-segunda Guerra Mundial. Neste período, o que está em jogo na questão das identidades é a desconstrução política, cultural, socioeconômica e todas as discussões que visam a questionamentos étnicos e nacionalistas, apegando-se aos vínculos territoriais. Encontramos esse jogo na voz de Hall (2006), ao sugerir o envolvimento da política, da cor, do sexo e da filosofia interferindo nas mudanças, de conformidade com a interpelação ou representação do sujeito.

Os resultados haviam sido experimentados em séculos anteriores, com projeções na atualidade. Exemplo claro sobre isso é colocado por Hall (2006, p. 20), ao se referir ao caso do juiz "negro" norte-americano, Clarence Thomas, indicado pelo presidente Bush para a Suprema Corte, e que tinha sido "acusado de assédio sexual por uma mulher negra", mas, por conta de sua ideologia política no que diz respeito à defesa da "legislação de igualdade de direito", viu levantar-se em torno de seu nome questões tipicamente ligadas ao "jogo de identidades". Estereótipos sobre liberalismo, raça e sexismo vieram à tona em severas discussões que apontavam a fragilidade das mudanças identitárias, como ele afirma:

Uma vez que a identidade muda de acordo como o sujeito é interpelado ou representado, a identificação não é automática, mas pode ser ganhada ou perdida. Ela tornou-se politizada. Esse processo é, às vezes, descrito como constituindo uma mudança de uma política de identidade (de classe) para uma política de diferença. (HALL, 2006, p. 21).

Isso deve ser considerado com base nas concepções idealistas da cultura suscitadas por Bakhtin (1988, p.36) ao identificar a palavra como "fenômeno ideológico por excelência". As transformações em apreço caminharam pelo viés da ideologia. Todo signo está sujeito aos critérios de avaliação ideológica (verdadeiro, falso, correto, bom), de modo que podemos crer que as mudanças identitárias se assentam também em bases semióticas e "tudo que é ideológico possui um valor semiótico" (BAKHTIN, 1988, p. 32).

Não se trata aqui de isolar e delimitar o referencial linguístico como objeto de estudo específico, como Bakhtin faz com a linguagem. Ele traz "duas orientações para todas as demais questões que se colocam em linguística", que chama de "subjetivismo idealista" e "objetivismo abstrato". Estes estão presentes nas variações linguísticas e trocas de costumes, nos deslocamentos identitários. Assim defende Bakhtin (1988, p. 82):

Os atos individuais de fala constituem, do ponto de vista da língua, simples refrações ou variação fortuitas ou mesmo deformações das formas normativas. Mas são justamente estes atos individuais de fala que explicam a mudança histórica das formas da língua; enquanto tal, a mudança é do ponto de vista do sistema, irracional e mesmo desprovida de sentido. Entre o sistema da língua e sua história não existe nem vínculos nem afinidade de motivos. Eles são estranhos entre si.

Assim sendo, a caracterização do objeto aqui proposto não pode ser fechado e delimitado somente no referencial linguístico, pois atinge os elementos 
culturais e as identidades advindas de todas as representações sugeridas e estratificadas nos interrelacionamentos dos fluxos identitários.

\section{Hibridismo e mito no intercâmbio identitário}

A característica de hibridação em Joinville vem de longa data. As listas de imigrantes pesquisadas e elaboradas por Böbel e Thiago (2010) contêm não apenas alemães, mas suíços e noruegueses e há, ainda, o fato de que os alemães vinham de diferentes regiões, o que nos leva a crer numa mescla cultural por meio do próprio processo imigratório que conduz os fluxos identitários.

Essa experiência provoca mudanças na visão de mundo e consequentes deslocamentos. Melhor dizendo, uma mudança no seu conceito de identidade ou na sua identificação. Descendentes de alemães que nasceram ou vivem em Joinville desde a década de 1930 interagem culturalmente numa realidade de conflito e, hoje, presenciam uma realidade cultural continuadamente híbrida, como afirma Coelho (2011, p. 30):

Joinville - como tantas outras cidades contemporâneas - pulsa (n)o tempo presente, marcado por disjunções, superposições e complexidades de fluxos de pessoas, tecnologias, finanças, imagens e informações. Seus paradoxos - visíveis e invisíveis - igualmente pulsam nos sujeitos (moradores da cidade) que vivenciam e promovem entrecruzamentos, mediações e hibridismos, desenrolando jogos entre semelhanças e diferenças.

A realidade é fruto da contrapartida que aparece com o processo migratório que, historicamente, veio fincar, também, na cidade outros ventos culturais de influência interna e externa. Revela um quadro ambivalente. Por um lado, sem atingir diretamente os descendentes germânicos e, por outro, como se pode verificar na historiografia local, tenta reforçar a tradição germânica, embora com uma filosofia de alguma maneira implantada, como se pode verificar com base na fala de Rosskamp (2012), que há uma tendência de se divulgar que "o ímpeto realizador" da cidade recai sobre a "força germânica".

Ao escrever sua introdução à edição de 2001 de Culturas híbridas, estratégias para entrar e sair da modernidade, Canclini (2008 p. XIX) entende "por hibridação processos socioculturais nos quais estruturas ou práticas discretas, que existiam de forma separada, se combinam para gerar novas estruturas, objetos e práticas". O autor parte da compreensão de que o que ele chama de "estruturas e práticas discretas" são, em tese, frutos de hibridação. Sustenta, ainda, que o seu "objeto de estudo não é a hibridez, mas, sim, os processos de hibridação".

Assim afirma Canclini (2008, p. 23):

A ênfase na hibridação não enclausura apenas a pretensão de estabelecer identidades "puras" ou "autênticas". Além disso, põe em evidência o risco de delimitar identidades locais autocontidas ou que tentem afirmar-se como radicalmente opostas à sociedade nacional ou à globalização. Quando se define uma identidade mediante um processo de abstração de traços (língua, tradições, condutas estereotipadas), frequentemente se tende a desvincular essas práticas da história de mistura em que se formaram. Como consequências é absolutizado um modo de entender a identidade e são rejeitadas maneiras heterodoxas de falar a língua, fazer música ou interpretar as tradições. Acaba-se, em suma, obturando a possibilidade de modificar a cultura e a política.

A tendência, em Joinville, segue o caminho da diversidade tanto étnica quanto cultural. Embora essa realidade não tenha sido motivo de abordagem no início de sua história, hoje é assim que se apresenta.

Conforme afirma Silva (2008, p. 39),

Uma cidade sempre apresenta múltiplas facetas, mas em Joinville, onde a presença dos teuto-brasileiros é grande e a história da imigração os privilegia, um discurso a constituiu como uma cidade germânica, numa operação de encobrimento da diversidade.

As entrevistas sinalizam experiências de transformações culturais. Alguns mantiveram o alemão como primeira língua, independentemente da obrigatoriedade de falar a língua portuguesa, ficando evidente que o discurso sobre as mudanças culturais foram decorrentes da proibição da língua no período da nacionalização - período político tenso que teve no referencial linguístico uma marca de poder.

A preservação da cultura dos antepassados é um elemento motivador, presente na prática discursiva, quando se trata da tentativa de persistência em se 
falar o idioma alemão. O processo proibitivo da língua se desloca também a outras atividades culturais e se repercute numa diminuição do desenvolvimento da cultura. E é esse elemento, a cultura, que mais aparece nos discursos, demonstrando que já não se leva tanto em consideração a questão linguística como sistema formal e fator de obrigatoriedade, mas sim a perda de identificações culturais. Ao mesmo tempo que se admite a perda da identidade linguística, esses descendentes também afirmam sua persistência em continuar estudando a língua e tentando, de alguma maneira, interagir com alguns remanescentes culturais. Situações demarcadas por falas como: "tenho interesse em me aprimorar" (BRUHNS, 2012); "Gostaria que os jovens se interessassem mais pela língua, o que eu não pude fazer” (TRINKS, 2012). As transformações culturais são fruto da inexistência de neutralidade no processo, como considera Decrosse $\left(1989\right.$, p. 19) ${ }^{9}$ ao descrever a língua materna como um mito:

Mas seria utopia acreditar que as línguas maternas tenham adquirido, de imediato, uma realidade. Bem ao contrário, a noção, o termo e os usos foram forjando, aos poucos, uma identidade através de séries de operações socioculturais, políticas e religiosas, das quais, cada momento tem uma identidade própria e estados linguísticos distintos.

A análise das entrevistas sinaliza que os indivíduos têm consciência do hibridismo existente como uma realidade histórica. Contudo, ainda lutam com um discurso identitário, como numa tentativa de retornar às origens. Nesse sentido, podemos entender que utilizam o discurso para afirmar a identidade cultural germânica como um mito, vista numa perspectiva de distanciamento da história para, assim, se instalar o "sabor da literatura", como no dizer de Barthes (2008, p. 21). A linguagem mítica existe por meio de significantes que são criados com base nos conceitos que formam o "determinado" linguístico. As narrativas compõem, portanto, as criações literárias que conduzem a identidades culturais. Estas, pode-se afirmar, situam-se no que Barthes (2008, p. 17) chama de forças da literatura, usando três conceitos gregos: mathesis, mimeses e semiosis - $\mu \alpha \theta \dot{\sigma} \sigma \mathrm{s}$,

\footnotetext{
${ }^{9}$ DECROSSE, Anne. Um mito histórico, a língua materna. In: VERMES, Geneviève; BOUTET, Josiane. (Org). Multilinguismo. Campinas, Unicamp, 1989.
}

ação de apreender, de se instruir, de receber conhecimento; $\mu \mu \eta \eta َ \sigma \iota$ - imitação, imagem, representação

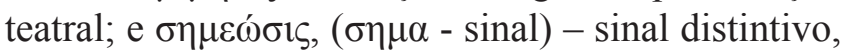
marca, aviso. Pela mathesis, a literatura traz todos os saberes; "pela mimesis, a literatura é usada para representar o real, embora este não se possa representar"; com a semiosis, ele joga com os signos e diz que essa é "a terceira força da literatura". É aqui, na semiologia, que Barthes situa o mito. Considera que ele saiu do original, da "linguística", interagiu com todas as áreas e se desconstruiu. Essa desconstrução Barthes chama "semiologia", (2008, p. 30). O discurso que advém, determina o mito identitário - "Pois o que pode ser opressivo num ensino não é finalmente o saber ou a cultura que ele veicula, são as formas discursivas através das quais ele é proposto." (BARTHES, 2008, p. 41).

O poder das narrativas, conforme afirma Campbell (1990 p. 6), são geradoras de “(...) pistas para as potencialidades da vida humana" e de uma "experiência de sentido".

Os elementos festivos, muito próprios da cultura alemã, apresentam-se como fator de nostalgia (VOIGT, BUTZKE, 2012). Com a campanha de nacionalização deflagrada pelo Estado Novo (19371945), tudo que era ligado a essa cultura foi considerado como "perigo alemão". Então, se de um lado podemos falar de mito na persistência de um processo identitário entre descendentes de alemães em Joinville, historicamente, contudo, não se pode negar que mitos da classe dominante das décadas de 1940 e 1950 também se encarregaram de implantar certas diferenças. A "unidade" presente nos discursos são, "na verdade, construídas no interior do jogo do poder e da exclusão" (HALL, 2000 p. 110).

É a convivência com as diferenças que instala o hibridismo. A linguagem é o elemento propulsor para o intercâmbio identitário. É a prática do discurso linguístico que cria o diálogo entre a identidade e as diferenças. "Além de serem interdependentes, identidade e diferença partilham uma importante característica: elas são resultantes de atos de criação linguística. [...] São criações sociais e culturais", (HALL, 2000 p. 76). Contudo, não devemos esquecer que essa relação é sóciodialética. Há, nela, a história recíproca do opressor e do oprimido. E, para concordar com Barthes (2001), o discurso do opressor é intransitivo e o do oprimido procura transformações. 
Sabe-se que o processo identitário cultural existe numa relação construtiva direta e proporcional ao saber local. As culturas são construções históricas bastante rígidas e facilmente adaptáveis a mitos. Foi essa condição, por exemplo, que fez com que Geertz (2009) analisasse, em sua obra "O saber local", a questão do direito. Essa análise é feita com base no ponto de vista da antropologia interpretativa, considerando os fatos sociais que interagem com leis. Cada sociedade tem suas leis e estas se adequam às realidades de suas crenças e costumes, interferindo na hermenêutica jurídica.

Assim, as identidades culturais se imbricam na formação de identidades e interferem, com juízos de valor, nos estatutos jurídicos. O direito também é visto como um fato cultural, tal qual a arte, a religião e outros, considerando que é desenvolvido numa relação direta com os contextos culturais. Geertz (2009, p. 255) coloca que há uma necessidade de um "ir e vir" hermenêutico entre o direito e o campo da antropologia e etnografia. Os fatos sociais, que garantem a hibridização e o surgimento dos mitos culturais, provam que já não basta conhecer somente as leis.

A tese de Geertz de que o direito é saber local, e, portanto, mais que leis, e ainda, submisso ao relativismo cultural, ajuda na compreensão de como as identidades são estabelecidas com base nos conhecimentos variados, independentemente da sua análise epistemológica pela sociedade que as constrói e defende. Isso é posto independentemente de cada povo, sociedade, cultura, tribo, etnia, etc.

Assim ele se expressa no final do capítulo oito:

O direito, com o seu poder de colocar acontecimentos específicos - um compromisso aqui, uma injúria acolá - em uma moldura geral de uma maneira tal, que as normas que regulam um gerenciamento adequado e probo desses acontecimentos pareçam surgir naturalmente dos elementos essenciais do seu caráter, é um pouco mais que um reflexo da sabedoria herdada, ou uma técnica para a resolução de conflitos. Com razão ele atrai para si o mesmo tipo de paixão que aqueles outros procriadores de significados e propositores de mundos - a religião, a ideologia, a ciência, a história, a moral e o senso comum - atraem. [...] O que está em risco, portanto, ou julga-se estar em risco, são as próprias concepções sobre o que é fato e sobre o que é a lei, e a relação que existe entre elas - a sensação sem a qual os seres humanos mal podem viver, quanto mais adjudicar seja lá o que for, de que a verdade, o vício, a mentira e a virtude são coisas reais, distinguíveis e estão alinhadas em seus devidos lugares. (GEERTZ, 2009, p. 349).

A convivência com o novo, com o diferente, pode não ter sido a mais aceita entre os descendentes de imigrantes alemães em Joinville, mas foi absorvida, gerou suas consequências e expôs mitos identitários que, sobre os quais, em épocas anteriores, as nações e o contexto sócio-histórico brasileiro ainda não tinham condições intelectuais de refletir. Da mesma forma, todas essas experiências só ajudaram a afirmar a cidade de Joinville como polo de diversidade cultural, inserida num contexto de diálogo cujo discurso é gerador de novas diversidades.

\section{Considerações finais}

A análise das entrevistas entre sete descendentes de alemães em Joinville - SC desvela representações dos desdobramentos culturais da imposição da língua portuguesa entre os sujeitos entrevistados de descendência alemã, os quais tinham, no alemão, a sua primeira língua. Os entrevistados sinalizaram que, em suas famílias, o interesse pela cultura alemã persiste, apesar de a língua materna circular com a língua portuguesa; demonstraram saudades dos ensinamentos dos antepassados, das rezas e valores transmitidos em língua materna.

Em relação às mudanças culturais, os resultados das entrevistas apontam que o desuso da língua materna foi crucial, o peso, segundo as impressões, recai sobre a língua, mas há registros variados que vão desde hábitos e características morais, esquecimento da língua materna e uma fala que lembra que "os casamentos deviam ser com cônjuges da mesma raça”. Os sujeitos também se referem, com saudades, aos eventos que envolviam música, danças, teatro e outras atividades culturais promovidas no intercâmbio familiar, o que era bastante costumeiro entre os imigrantes alemães e seus descendentes, pelo menos até a instituição do Estado Novo com a era varguista. Eram esses elementos que ajudavam na manutenção da convivência linguística e consequentemente na disseminação da "cultura germânica".

Os dados reafirmam que o período pós Primeira Guerra Mundial foi conturbado. Contudo, foi 
possível perceber que o trabalho e a produtividade que os imigrantes e descendentes assumiram em Joinville facilitou a adaptação em terras tropicais. Lutas e enfrentamentos aconteceram, constituindo-se como parte da resistência inicial para a convivência e fruto da reflexão entre os imigrantes e descendentes sobre a identificação com a qual teriam que se relacionar. Eles viram, como resultado, a diminuição da produção de seus próprios alimentos, o medo de se instalar, os conflitos existenciais aumentarem, a castração de eventos culturais e a desmotivação pelo elemento festivo.

Dois fatores concorreram para o intercâmbio identitário. Primeiro a pressão política e a sua consequente projeção sobre as famílias dos imigrantes, gerando medo e desconforto. Em segundo lugar, o convívio com a língua portuguesa. Esses fatores fizeram com que os usos e costumes públicos que dependiam da expressão linguística começassem a entrar em esquecimento. As transformações, portanto, passam pelo viés linguístico e repercutem em um novo perfil de identidade. Esse novo perfil é marcado por um aspecto idealizado e recupera tradições buscadas nas suas memórias.

\section{Referências}

ALTENHOFEN, C. V. Política linguística, mitos e concepções linguísticas em áreas bilíngues de imigrantes (alemães) no sul do Brasil. Revista Internacional de linguística Ibero americana, Frankfurt, v.3, 2004.

BAKHTIN, M. Marxismo e filosofia da linguagem. São Paulo: Hucitec, 1988.

BARTHES, R. Aula, São Paulo: Cultrix, 2008.

. Mitologias. Rio de Janeiro: Bertrand Brasil, 2001.

BÖBEL, M. T.; THIAGO, R. S. Joinville: os pioneiros, documento e história. Joinville: UNIVILLE, 2010. v.1.

BOURDIEU, P. O poder simbólico. Rio de Janeiro: Bertrand Brasil, 2002.

BRUHNS, I. Iracema Bruhns. Entrevista [26 Abril 2012]. Entrevistador: Jailson Estevão dos Santos. Joinville-SC. abril 2012.

BUTZKE, A. André Butzke. Entrevista [26 abril 2012]. Entrevistador: Jailson Estevão dos Santos. Joinville-SC. Abril 2012.

CAMPBELL, J. O poder do mito: Joseph Campbell com Bill Moyers. São Paulo: Palas Athena, 1990.
CANCLINI, N. G. Culturas híbridas, estratégias para entrar e sair da modernidade. São Paulo: Ed. EDUSP. 2008.

CANDAU, J. Memória e identidade. São Paulo: Contexto, 2011.

COELHO, I. Joinville e a campanha da nacionalização. São Carlos, 1993. 139 f. Dissertação (Mestrado em Ciências Sociais) - Universidade Federal de São Carlos.

Pelas tramas de uma cidade migrantes. Joinville: Ed. Univille, 2011.

DECROSSE, A. Um mito histórico, a língua materna. In: VERMES, G.; BOUTET, J. (Org). Multilinguismo. Campinas, Unicamp, 1989.

DE LUCA, T. R. Leituras, projetos e (re)vista(s) do BRASIL (1916 -1944). São Paulo: Unesp, 2011.

GALLO, S. M. L. Ciência e cultura: universalidade ou identidade? In: NECKEL, N. R. M. (Org.). Ciência e cultura. Palhoça. UNISUL, 2011, p. 11.

GEERTZ, C. O saber local, novos ensaios em antropologia interpretativa. Petrópolis: Vozes, 2009.

GUEDES, S. P. L. C. (Org.). Histórias de (i)migrantes: o cotidiano de uma cidade. Joinville: UNIVILLE, 2005.

HALL, S. A identidade cultural na pós-modernidade. Rio de Janeiro: DP\&A Editora, 2006.

2000.

Identidade e diferença. São Paulo: Ed. Vozes, Quem precisa de identidade? In: SILVA, T. T. (Org.).

Identidade e diferença: a perspectiva dos estudos culturais. Petrópolis: Vozes 2002.

HARDT, H. Humberto Hardt. Entrevista [26 Abril 2012]. Entrevistador: Jailson Estevão dos Santos.

HOBSBAWN, E.; RANGER, T. (Orgs.). A invenção das tradições. Rio de Janeiro: Paz e Terra, 1984.

O TREM DA VIDA. Direção de Radu Mihaileanu, Bélgica, França, Holanda, 1998, color, 103 min.

POLLAK, M. Memória, esquecimento, silêncio. Rio de Janeiro: Estudos históricos, v. 2 , n.3, 1989.

REIS, A. Asta dos Reis. Entrevista [26 abril 2012]. Entrevistador: Jailson Estevão dos Santos. Joinville-SC. Abril 2012.

ROSSKAMP, R. Raulino Rosskamp. Entrevista [26 abril 2012]. Entrevistador: Jailson Estevão dos Santos. JoinvilleSC. Abril 2012.

ROST, C. A. A identidade do teuto-brasileiro na região sul do Brasil. UFSC, 2008. Disponível em: <http://www. posgrap.ufs.br/periodicos/interdisciplinar/revistas/ARQ INTER_5/INTER5_pg_215_236.pdf > . Acesso em: 19 maio 2011. 
SAUSSURRE, F. Curso de linguística geral. São Paulo: Cultrix, 1975.

SEM PALAVRAS (documentário). Direção de Kátia Clock. Florianópolis, Contraponto produtora, 2009.

SEYFERTH, G. Imigração e cultura no Brasil. Brasília: Universidade de Brasília, 1990.

Nacionalismo e identidade étnica. Florianópolis: Fundação Catarinense de Cultura, 1981.

SILVA, J. G. Tempo de lembrar, tempo de esquecer: as vibrações do centenário e o período da nacionalização: histórias e memórias sobre a cidade de Joinville. Joinville: Univille, 2008.

SILVA, T. T. (Org.). Identidade e diferença: a perspectiva dos Estudos Culturais. Petrópolis: Vozes, 2000.

SPINASSÉ, K. P. Os imigrantes alemães e seus descendentes no Brasil: a língua como fator identitário inclusivo. (UFRS), 2008. Disponível em: <www.msmidia.com/ conexao/3/cap10.pdf> . Acesso em: 19 maio 2011.

THIAGO, R. S. Tempos de Joinville. Joinville: Univille, 2008.

TRINKS, M. E. Myrta Ebrhardt Trinks. Entrevista [26 abril 2012]. Entrevistador: Jailson Estevão dos Santos. Joinville-SC. Abril/2012.

VOIGT, V. Vilson Voigt. Entrevista [26 abril 2012]. Entrevistador: Jailson Estevão dos Santos. Joinville-SC. Abril 2012.

Recebido em: 23 de fevereiro de 2013. Aceito em: 24 de maio de 2013. 